\title{
Oral administration of GLPG0259, an inhibitor of MAPKAPK5, a new target for the treatment of rheumatoid arthritis: a phase II, randomised, double-blind, placebo-controlled, multicentre trial
}

\author{
René Westhovens, ${ }^{1}$ Filip De Keyser, ${ }^{2}$ Dmytro Rekalov, ${ }^{3}$ Evgeny L Nasonov, ${ }^{4}$ \\ Johan Beetens, ${ }^{5}$ Annegret Van der $A a_{1}{ }^{5}$ Piet Wigerinck, ${ }^{5}$ Florence Namour, ${ }^{6}$ \\ Frédéric Vanhoutte, ${ }^{5}$ Patrick Durez ${ }^{7}$
}

\begin{abstract}
- Additional data are published online only. To view these files please visit the journal online (http://dx.doi.org/ 10.1136/annrheumdis-2012202221).

'Department of Rheumatology, University Hospital KU Leuven, Leuven, Belgium

${ }^{2}$ Department of Rheumatology, Ghent University Hospital,

Ghent, Belgium

${ }^{3}$ Department of Rheumatology, Zaporizhzhia Regional Hospital, Zaporozhe, Ukraine

${ }^{4}$ Department of Rheumatology, Institute of Rheumatology,

Moscow, Russia

${ }^{5}$ Clinical Development Department, Galápagos NV,

Mechelen, Belgium

${ }^{6}$ Clinical Development

Department, Galápagos SASU,

Romainville, France

${ }^{7}$ Department of Rheumatology, Université Catholique de

Louvain, Brussels, Belgium
\end{abstract}

\section{Correspondence to}

Dr Frédéric Vanhoutte, Galápagos NV, Gen De Wittelaan L11 A3, Mechelen 2800, Belgium; Frederic.Vanhoutte@glpg.com

Accepted 20 October 2012 Published Online First

17 November 2012

\section{ABSTRACT}

Background Mitogen-activated protein (MAP) kinases are key regulators of cytokine production, and are therefore potential targets for treatment of rheumatoid arthritis (RA)

Objective This two-part phase II study investigated the efficacy and safety of a once-daily 50 mg GLPG0259 (an inhibitor of MAP kinase-activated protein kinase 5) dose vs placebo (part A). An interim analysis after part $A$ would determine whether the dose-finding part (part B) would be performed.

Methods In part A, eligible methotrexate (MTX)refractory patients with $\mathrm{RA}$ were randomised to receive either a once-daily $50 \mathrm{mg}$ dose of GLPG0259 or placebo, in addition to a stable dose of MTX, for 12 weeks. The primary efficacy end point was the percentage of patients achieving an American College of Rheumatology 20\% improvement (ACR20) response after 12 weeks. Results The interim analysis showed no difference between the percentage of subjects achieving the primary efficacy variable of ACR20 or the secondary efficacy variables (ACR50, ACR70 and Disease Activity Score 28) at week 12 in the GLPG0259-treated $(n=19)$ and placebo-treated $(n=11)$ groups. Owing to lack of efficacy, the study was terminated, and part B was not initiated.

Conclusions This innovative study design quickly provided conclusive results on the lack of efficacy of GLPG0259 in patients with RA.

\section{INTRODUCTION}

A key component of rheumatoid arthritis (RA) is inflammation of the synovial membrane, accompanied by overexpression of several proinflammatory cytokines. ${ }^{1-3}$

Mitogen-activated protein (MAP) kinases (eg, p38 group) are key regulators of proinflammatory cytokine and metalloproteinase production. MAP kinase-activated protein kinase 5 (MAPKAPK5) has recently been identified in synovial fibroblasts of patients with RA as a potential new target for treatment. ${ }^{4}$ MAPKAPK5 is involved in a transduction pathway that leads to the secretion of catabolic enzymes such as matrix metalloproteinase 1, which can cause damage to bone and cartilage.
GLPG0259 is a first-in-class, small-molecule ATP-competitive inhibitor of MAPKAPK5. In cellular assays, GLPG0259 reduced the release of several mediators of inflammation and bone degradation better than or comparable to inhibitors of p38, janus activated kinase (JAK) and spleen tyrosine kinase (SYK). GLPG0259 did not block phosphorylation of c-jun $\mathrm{NH}(2)$-terminal protein kinase (JNK), ERK and p38 MAP kinases, indicating inhibition of a kinase downstream in cytokine-response pathways. In addition, oral administration of GLPG0259 reduced inflammation and bone destruction in the mouse collagen-induced arthritis model. ${ }^{5}$

In phase I studies in healthy male subjects, the maximum tolerated dose was established at $50 \mathrm{mg} /$ day - a safe and well-tolerated dose when co-administered with a single dose of $7.5 \mathrm{mg}$ methotrexate (MTX). ${ }^{6}$ The pharmacokinetic profile in phase I studies supported a once-daily oral dosing regimen.

The innovative trial design used here allows a complete phase II programme to be carried out in a single study.

\section{METHODS}

\section{Patients}

Between November 2010 and March 2011, patients with active RA and an inadequate response to MTX were treated for 12 weeks. See online supplementary text for detailed inclusion and exclusion criteria.

\section{Trial design}

This was a phase II, randomised, double-blind, placebo-controlled, multicentre trial (NCT01211249). Part A (proof-of-concept) was designed to establish efficacy and safety of a once-daily dose of $50 \mathrm{mg}$ GLPG0259 compared with placebo, in addition to a stable dose of MTX, over 12 weeks. It included 30 patients. A subsequent interim analysis of the results from part $A$ would determine whether part $B$ (dose finding) would be initiated. Part B was designed to increase the maximum number of patients to 200 , spread over four dose groups (high, middle, low, placebo). This trial design limits the number of patients exposed to high dose and placebo by including in part B data from patients receiving these doses in part A. More details on the study design are 


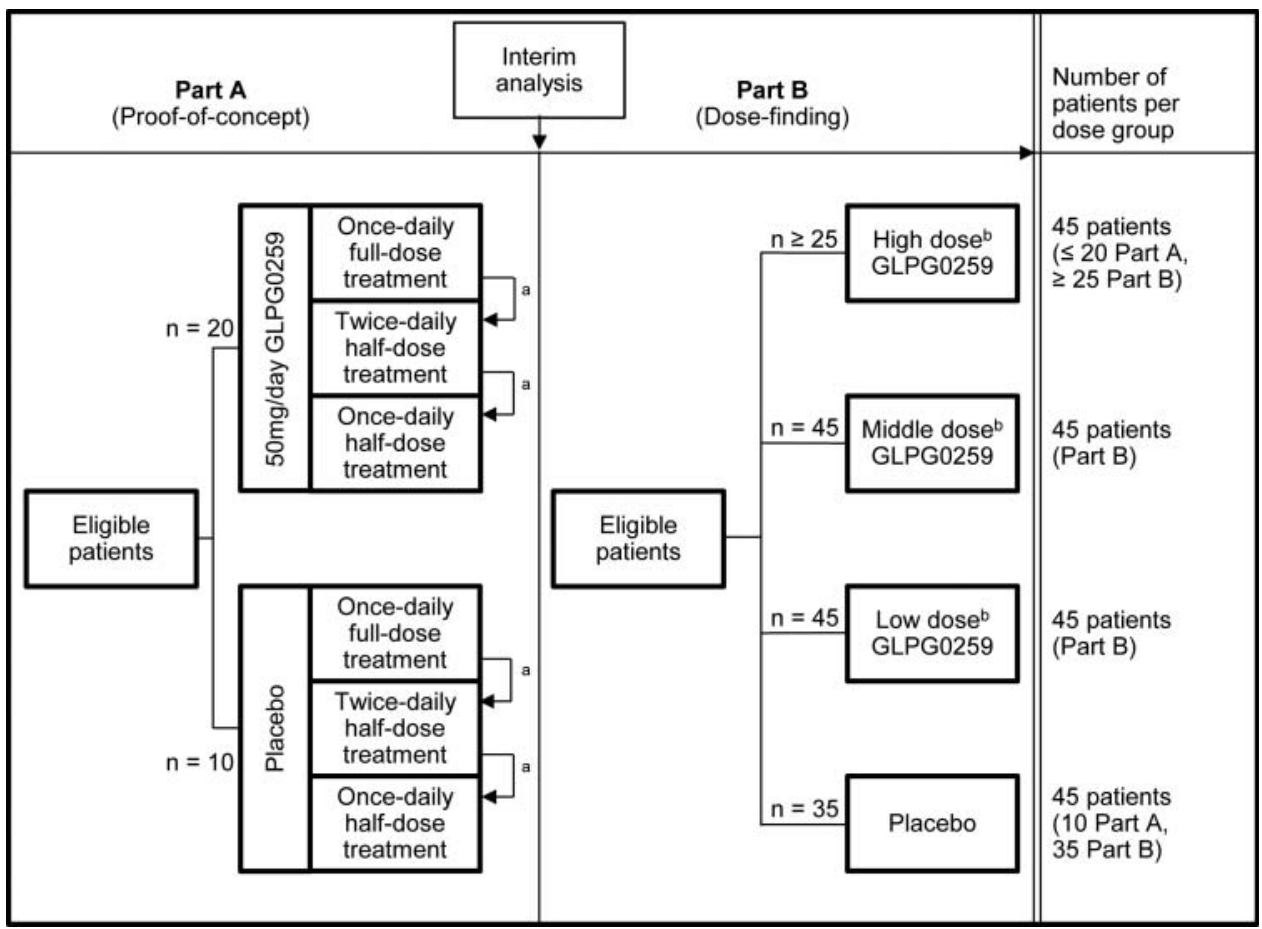

Figure 1 Design of the exploratory, randomised, double-blind, placebo-controlled, multicentre phase II trial. Duration and assessment schedule were the same for part $A$ and part $B$.

aff the $50 \mathrm{mg} /$ day dose was not tolerated by the patient, the investigator could decide to either split (twice-daily half-dose treatment) or reduce (once-daily half-dose treatment) the daily dose.

${ }^{\text {b} T h e ~ h i g h e s t ~ d o s e ~ s e l e c t e d ~ d e p e n d s ~ o n ~ t h e ~ t o l e r a b i l i t y ~ o f ~ t h e ~ d r u g . ~ I f ~ t h e ~ h i g h e s t ~ d o s e ~ s e l e c t e d ~ f o r ~ P a r t ~ B ~ w a s ~} 50$ mg/day, the 'High', 'Middle' and 'Low' dose groups received $50 \mathrm{mg}, 25 \mathrm{mg}$ and $12.5 \mathrm{mg}$ of GLPG0259 respectively per day. If the highest dose selected for Part B was $25 \mathrm{mg} / \mathrm{day}$, the 'High', 'Middle' and 'Low' dose groups received $25 \mathrm{mg}, 12.5 \mathrm{mg}$ and $6 \mathrm{mg}$ of GLPG0259, respectively, per day.

presented in figure 1 and the online supplementary text. The study was conducted in accordance with the Declaration of Helsinki and was consistent with the International Conference on Harmonisation of Good Clinical Practice.

\section{Efficacy}

The primary efficacy variable was American College of Rheumatology 20\% improvement (ACR20) response at week 12. The secondary efficacy variables were: ACR20 response in each treatment group at weeks 1, 2, 4 and 8; time to ACR20 response, ACR50/ACR70 response, and change from baseline in Disease Activity Score 28 (DAS28) using C-reactive protein (CRP) at weeks 1, 2, 4, 8 and 12 .

\section{Safety}

Safety data were summarised for the safety population (all randomised patients who received one or more doses of GLPG0259). Reported adverse events were coded using the Medical Dictionary for Regulatory Activities 13.1 or higher (see online supplementary text).

\section{Pharmacokinetics}

The pharmacokinetic analysis was descriptive, using plasma concentrations of GLPG0259.

\section{Statistical analysis}

For the interim efficacy analysis, a selection of efficacy variables were summarised for the intention-to-treat (ITT) population (all randomised patients receiving $\geq 1$ dose of GLPG0259 and provided data for $\geq 1$ post-baseline efficacy assessment). The ACR responses and DAS28 were derived using SAS V.9.1.3 or later.

\section{RESULTS}

Baseline demographics

Of the 69 patients screened, 31 met the inclusion criteria and were randomised $(2: 1)$ to receive $50 \mathrm{mg}$ /day GLPG0259 $(n=20)$ or placebo $(n=11)$. One patient (GLPG0259 group) discontinued the treatment because of low back pain which occurred before treatment.

No clinically or biologically meaningful demographic or baseline differences were found between the groups (table 1).

No patient had been treated with biological agents before enrolment.

Thirty patients (19 in the GLPG0259 group; 11 in the placebo group) received $\geq 1$ dose of treatment and were included in the safety population. All patients had $\geq 1$ post-baseline efficacy assessment and were included in the ITT population. Thus, safety and ITT populations were identical.

Of these 30 patients, 27 (87.1\%) completed the study: $17(85.0 \%)$ in the GLPG0259 group and $10(90.9 \%)$ in the placebo group; two withdrew consent (1 per group) and one discontinued for private reasons (GLPG0259 group). Four (20.0\%) patients in the GLPG0259 group required their dose to be split (twice $25 \mathrm{mg} /$ day); no patient required a dose reduction.

\section{Primary efficacy variable}

Five patients (26.3\%) in the GLPG0259 group and three patients $(27.3 \%)$ in the placebo group achieved an ACR20 response at week 12 (table 2 ). The ACR20 response rate in the 
Table 1 Baseline characteristics and disease status (safety/ITT population)

\begin{tabular}{|c|c|c|}
\hline & GLPG0259 (n=19) & Placebo $(n=11)$ \\
\hline \multicolumn{3}{|l|}{ Baseline characteristics } \\
\hline Age (years) & $50(27,69)$ & $52(30,64)$ \\
\hline Sex (male/female) & $5 / 14$ & $4 / 7$ \\
\hline Race (Caucasian) & 19 & 11 \\
\hline Height $(\mathrm{cm})$ & $169(159,180)$ & $169(158,194)$ \\
\hline Weight (kg) & $74(47,98)$ & $75(49,95)$ \\
\hline BMI $\left(\mathrm{kg} / \mathrm{m}^{2}\right)$ & $25.9(16.9,38.3)$ & $26.6(17.8,35.8)$ \\
\hline \multicolumn{3}{|l|}{ Disease status at screening } \\
\hline RF positive & $73.7 \%$ & $90.9 \%$ \\
\hline Anti-CCP positive & $78.9 \%$ & $81.8 \%$ \\
\hline RF and anti-CCP positive & $73.7 \%$ & $81.8 \%$ \\
\hline Serum CRP (mg/l) & $52(18,122)$ & $41(16,107)$ \\
\hline \multicolumn{3}{|l|}{ Disease status at baseline } \\
\hline Serum CRP (mg/l) & $37(2,129)$ & $34(5,97)$ \\
\hline SJC66 & $12(6,19)$ & $15(5,33)$ \\
\hline TJC68 & $20(7,35)$ & $23(0,35)$ \\
\hline DAS28 (CRP) & $5.83(4.98,7.27)$ & $6.12(5.17,7.20)$ \\
\hline Use of oral steroids & $57.9 \%$ & $63.6 \%$ \\
\hline Current dose of MTX (mg/week) & $10.66(7.5-20)$ & $11.36(7.5-20)$ \\
\hline
\end{tabular}

Age expressed as median (range); height, weight, BMI, serum CRP, SJC66, TJC68, DAS28 (CRP) and current dose of MTX expressed as mean (range).

$\mathrm{BMI}$, body mass index; CCP, cyclic citrullinated peptide; CRP, C-reactive protein;

DAS, Disease Activity Score; ITT, intention-to-treat; MTX, methotrexate; RF,

rheumatoid factor; SJC, swollen joint count; TJC, tender joint count.

placebo group was as expected and at a similar level as used in the sample size calculation.

\section{Secondary efficacy variables}

No patient achieved an ACR20 response at week 1 . At weeks 2 and 4 , the response rate in the placebo group was $27.3 \%$; at week 8 , it increased to $45.5 \%$, and stabilised back to $27.3 \%$ by the end of the treatment period. The response rate in the GLPG0259 group increased from 10.5\% at weeks 2 and 4 to $21.1 \%$ at week 8 and $26.3 \%$ by the end of the treatment period (table 2).

The median time to ACR20 response among ACR20 responders was 41.0 days (GLPG0259 group) and 20.5 days (placebo group).

One (5.3\%) patient in the GLPG0259 group and two (18.2\%) in the placebo group achieved an ACR50 response at week 8. No other patients achieved an ACR50 response at any other time point. No patient achieved an ACR70 response at any time.
In the GLPG0259 group, the mean decrease from baseline DAS28 (CRP) did not exceed 0.6 across the visits, while in the placebo group it was just over 1.1 at both weeks 8 and 12 .

Mean changes from baseline CRP showed a consistently larger decrease in the GLPG0259 group over the 12-week treatment period compared with the placebo group (table 2).

\section{Safety}

GLPG0259 at $50 \mathrm{mg} /$ day over 12 weeks was considered safe and well-tolerated, with observed treatment-emergent adverse events (TEAEs) consistent with the expected safety profile (see online supplementary text and online supplementary table S1). No serious TEAEs or TEAEs leading to study discontinuation were reported.

\section{Pharmacokinetics}

Plasma GLPG0259 concentrations were well within the range observed in healthy volunteers at the same dose level (see online supplementary text and online supplementary figure S1).

\section{DISCUSSION}

The interim analysis of the primary efficacy variable (ACR20) showed that $50 \mathrm{mg}$ GLPG0259 orally administered once daily is not superior to placebo. The innovative phase II study design allowed early independent analysis and evaluation of proof-of-concept data, eventually resulting in discontinuation of the study. All secondary efficacy variables showed results consistent with those of the primary efficacy end point. This study also confirmed the results of previous phase I studies ${ }^{6}$ indicating that GLPG0259 is well tolerated at a once-daily $50 \mathrm{mg}$ dose.

The lack of efficacy may be explained by the following. (1) The impact of MAPKAPK5 inhibition on the pathogenesis of RA has not yet been demonstrated in patients. (2) Although plasma exposures in patients were similar to exposures to active dosages in animal models, data indicating that the enzyme pathway is significantly inhibited at current plasma concentrations in the target tissues of patients are lacking. However, reduced CRP levels suggest some effectiveness of the administered dose. Higher dosages were not tested because of safety considerations. (3) This particular inflammation pathway is a complex pathway, and multiple modalities are involved in activation and inhibition. Blocking one involved kinase may lead to compensatory effects in the others. The number of failed studies with p38 MAPK inhibitors lends some weight to this.

There is a need for oral drugs that are effective in treating RA. Several drugs in development have targeted recently identified pathways ${ }^{7}{ }^{8}$; however, not all have shown efficacy. ${ }^{9}$ Trial designs such as ours will help shorten the development process.

Table 2 ACR20 response rates and CRP levels during the 12-week study period

\begin{tabular}{|c|c|c|c|c|}
\hline & \multicolumn{2}{|l|}{$\underline{\text { ACR20 responders, } \mathrm{n}(\%)}$} & \multicolumn{2}{|l|}{ CRP (mg/l) } \\
\hline & GLPG0259 $50 \mathrm{mg} / \mathrm{day}(\mathrm{n}=19)$ & Placebo $(n=11)$ & GLPG0259 50 mg/day (n=19) & Placebo $(n=11)$ \\
\hline Baseline & & & $36.5 \pm 8.1$ & $34.0 \pm 9.1$ \\
\hline Week 1 & 0 [NA] & $0[\mathrm{NA}]$ & $37.9 \pm 6.8$ & $39.1 \pm 10.2$ \\
\hline Week 2 & $2(10.5)[1.3$ to 33.1$]$ & $3(27.3)$ [6.0 to 61.0$]$ & $23.5 \pm 3.3$ & $37.2 \pm 11.3$ \\
\hline Week 4 & 2 (10.5) [1.3 to 33.1] & $3(27.3)$ [6.0 to 61.0$]$ & $25.4 \pm 4.7$ & $50.1 \pm 15.5$ \\
\hline Week 8 & $4(21.1)[6.1$ to 45.6$]$ & $5(45.5)$ [16.7 to 76.6$]$ & $29.1 \pm 4.3$ & $40.8 \pm 11.2$ \\
\hline Week 12 & 5 (26.3) [9.1 to 51.2] & 3 (27.3) [6.0 to 61.0] & $27.0 \pm 4.5$ & $42.5 \pm 12.4$ \\
\hline
\end{tabular}

Square brackets contain $95 \%$ Cls. CRP values presented as mean \pm SEM.

Last observation carried forward was applied to each component variable of the ACR20 response calculation. Percentages were calculated based on the number of patients in the intention-to-treat population in each treatment group.

ACR20, American College of Rheumatology $20 \%$ improvement in disease activity; CRP, C-reactive protein; NA, not applicable. 
Our innovative trial design makes a complete phase II programme possible in a single study. The interim analysis provided results very quickly. Hence, the study could be terminated more quickly, thus limiting the number of subjects exposed to a drug in early development or to placebo. In general, small numbers of patients can be used in well-defined disease areas, where historical placebo response data can validate any effects observed. If the experimental medication does not show a predefined substantial increment in effect, as benchmarked by active drugs in the market, a clear cut answer can be obtained. To ensure that a novel compound is not unduly discontinued, advice from an external expert panel that has reviewed all available data is essential.

In summary, this phase II study of oral GLPG0259 was the first to investigate the efficacy of small-molecule inhibition of MAPKAPK5, a new target for the treatment of RA. Further investigations on drugs aimed at potential targets for the treatment of RA are warranted.

Acknowledgements This study was supported by Galápagos. PharmaNet/i3 was responsible for the operational management of the clinical trial. The authors would like to acknowledge the following investigators who were involved in the recruitment of patients for study NCT01211249: Professor L I Dvoretskiy, Professor M F Ballyuzek, Dr I S Sardaryan, Dr V S Nemirovskiy, Dr B I Palamar, Professor V V Povoroznyuk, Dr L G Kononenko and Professor M A Stanislavchuk. The authors would also like to thank Professor I McInnes, Professor R F van Vollenhoven and Professor P C Taylor who were involved in the interim analysis of the data, CRO's Dr A La Noce and Dr 0 Boyarskaya from PharmaNet/33, and Dr K Oreskovic, Dr M De Weer and Dr I Van der Taelen from Galápagos.

Contributors All authors were involved in drafting the article and revising it critically for important intellectual content. All authors approved the final version for publication. FV, JB, FN, AVdA, PW, RW, FDK and PD were responsible for study conception and design. RW, PD, DR and ELN acquired the data. JB, AVdA, PW, FN, FV and RW analysed and interpreted the data.
Funding Writing support was provided by Archimed Medical Communication ag, Zofingen, Switzerland.

Competing interests $\mathrm{JB}, \mathrm{AVdA}, \mathrm{PW}, \mathrm{FN}$ and FV are employees of Galápagos. RW, FDK, DR, ELN and PD received a research grant from Galápagos.

Ethics approval The clinical study protocol, informed consent document(s), and any other appropriate study-related documents were reviewed and approved by the independent ethics committees and/or competent authorities.

Provenance and peer review Not commissioned; externally peer reviewed.

\section{REFERENCES}

1. Firestein GS. Evolving concepts of rheumatoid arthritis. Nature 2003;423:356-61.

2. Smolen JS, Steiner G. Therapeutic strategies for rheumatoid arthritis. Nat Rev Drug Discov 2003;2:473-88.

3. Smolen JS, Aletaha D, Koeller M, et al. New therapies for treatment of rheumatoid arthritis. Lancet 2007;370:1861-74.

4. Andrews M, Brys R, Vandeghinste $\mathrm{N}$, et al. Small molecules against the novel target MAPKAPK5 show bone protection and anti-inflammatory activity in in vivo models of rheumatoid arthritis. Ann Rheum Dis 2009; 68(Suppl 3):590.

5. Pujuguet P, Vandeghinste N, Dupont S, et al. GLPG0259, an inhibitor of novel target MAPKAPK5, dose-dependently reduces pro-inflammatory cytokines and MMPs and blocks disease progression in vivo. Ann Rheum Dis 2011;70(Suppl 3):275.

6. Namour F, Vanhoutte FP, Beetens J, et al. Pharmacokinetics, safety and tolerability of GLPG0259, a MAPKAPK5 inhibitor, given as single and multiple doses to healthy male subjects. Drugs $R$ D 2012;12:141-63.

7. McInnes IB, Schett $\mathrm{G}$. The pathogenesis of rheumatoid arthritis. N Engl J Med 2011;365:2205-19.

8. Yazici Y, Regens AL. Promising new treatments for rheumatoid arthritis—-the kinase inhibitors. Bull NYU Hosp Jt Dis 2011;69:233-7.

9. Landewé RB, Houbiers JG, Van den Bosch F, et al. Intranasal administration of recombinant human cartilage glycoprotein-39 as a treatment for rheumatoid arthritis: a phase II, multicentre, double-blind, randomised, placebo-controlled, parallel-group, dose-finding trial. Ann Rheum Dis 2010;69:1655-9. 


\section{ARD}

Oral administration of GLPG0259, an inhibitor of MAPKAPK5, a new target for the treatment of rheumatoid arthritis: a phase II, randomised, double-blind, placebo-controlled, multicentre trial

René Westhovens, Filip De Keyser, Dmytro Rekalov, et al.

Ann Rheum Dis 2013 72: 741-744 originally published online November 17,2012

doi: 10.1136/annrheumdis-2012-202221

Updated information and services can be found at:

http://ard.bmj.com/content/72/5/741.full.html

\section{These include:}

Data Supplement

"Supplementary Data"

http://ard.bmj.com/content/suppl/2012/11/17/annrheumdis-2012-202221.DC1.html

References This article cites 8 articles, 1 of which can be accessed free at: http://ard.bmj.com/content/72/5/741.full.html\#ref-list-1

Email alerting

Receive free email alerts when new articles cite this article. Sign up in the box at the top right corner of the online article. service

Topic Articles on similar topics can be found in the following collections Collections

Connective tissue disease (3302 articles)

Degenerative joint disease (3579 articles)

Immunology (including allergy) (3899 articles)

Musculoskeletal syndromes (3837 articles)

Rheumatoid arthritis (2503 articles)

Notes

To request permissions go to:

http://group.bmj.com/group/rights-licensing/permissions

To order reprints go to:

http://journals.bmj.com/cgi/reprintform

To subscribe to BMJ go to:

http://group.bmj.com/subscribe/ 